\title{
In silico identification and molecular characterization of genes predominantly expressed in the fish oocyte Julien Bobe*1, Thaovi Nguyen ${ }^{1}$, Sophie Mahé ${ }^{1}$ and Philippe Monget $^{2}$
}

Address: 'INRA, UR1337, IFR140, Ouest Genopole, Campus de Beaulieu, F-35000 Rennes, France and 2INRA, PRC, F-37380, Nouzilly, France Email: Julien Bobe* - julien.bobe@rennes.inra.fr; Thaovi Nguyen - tnguyen@rennes.inra.fr; Sophie Mahé - sophie.mahe@rennes.inra.fr; Philippe Monget - monget@tours.inra.fr

* Corresponding author

Published: 23 October 2008

BMC Genomics 2008, 9:499
Received: 16 July 2008

Accepted: 23 October 2008

This article is available from: http://www.biomedcentral.com/147I-2164/9/499

(c) 2008 Bobe et al; licensee BioMed Central Ltd.

This is an Open Access article distributed under the terms of the Creative Commons Attribution License (http://creativecommons.org/licenses/by/2.0), which permits unrestricted use, distribution, and reproduction in any medium, provided the original work is properly cited.

\begin{abstract}
Background: In fish, molecular mechanisms that control follicle-enclosed oocyte progression throughout oogenesis and oocyte developmental competence acquisition remain poorly understood. Existing data in mammals have indicated that the so called "oocyte-specific" genes play an important role in oogenesis, fertilization, and early embryo development. In teleost species, very little is known about "oocyte-specific" genes. The present study therefore aimed at identifying and characterizing oocyte-specific genes in fish.
\end{abstract}

Results: Using digital differential display PCR, mouse ESTs exhibiting an oocyte-predominant expression were identified. Those murine ESTs were subsequently used to identify cognate rainbow trout (Oncorhynchus mykiss) ESTs using a reciprocal Blast search strategy. In the present study we report the identification of five previously uncharacterized rainbow trout cDNAs exhibiting a oocyte-specific, oocyte-predominant, or gonad-specific expression: zygote arrest I (zarl), v-mos Moloney murine sarcoma viral oncogene-like protein (mos), B-cell translocation gene (btg3), growth differentiation factor 9 (gdf9), and mutS homolog 4 (msh4). The orthology relationship of each of these genes with vertebrate counterparts was verified by phylogenetic analysis. Among those five genes, three had never been characterized in any fish species. In addition, we report the oocyte-predominant expression of btg3 for the first time in any vertebrate species. Finally, those five genes are present in unfertilized eggs as maternally-inherited mRNAs thus suggesting that they could participate in ovarian folliculogenesis as well as early embryonic development.

Conclusion: The expression patterns of zarl, mos, btg3, gdf9 and msh 4 in rainbow trout and the functions of their orthologs in higher vertebrates strongly suggest that they might play an important role in follicle-enclosed oocyte development, meiosis control and early embryonic development in fish. Future investigations are however required to unravel the participation of those strong candidates in the molecular processes that control folliculogenesis and/or oocyte developmental competence in fish. 


\section{Background}

Oocyte developmental competence can be defined as the oocyte ability to be fertilized and to subsequently develop into a normal embryo. In fish, molecular mechanisms that control oocyte developmental competence remain poorly understood. In the past few years, transcriptomic investigations have been initiated to tentatively link oocyte transcriptome and oocyte developmental potential in order to identify key genes involved in the control of oocyte developmental competence [1]. While these types of approaches have been successful, information on the specific molecular mechanisms that make a good oocyte are still limited. One alternative way to fully understand the molecular mechanisms controlling oocyte quality is to study genes that are specifically or predominantly expressed in the oocyte. In mammals it has been shown that the so called "oocyte-specific" genes can affect folliculogenesis, fertilization and early development [2-4]. These genes have been extensively studied in mammals. Yet, very little information is available about those genes in fish despite the recent identification of ovarian-predominant genes in zebrafish [5]. The purpose of the present study was therefore to identify and characterize genes exhibiting a predominant oocyte expression in fish. Taking advantage of the numerous murine tissue-specific libraries available in public databases, we used an in silico approach to identify genes exhibiting an oocyte-predominant expression in rainbow trout (Oncorhynchus mykiss). Our study led to the identification and characterization of five previously uncharacterized rainbow trout cDNAs exhibiting an oocyte-specific, oocyte-predominant, or gonad-specific expression: zygote arrest 1 (zar1), v-mos Moloney murine sarcoma viral oncogene-like protein (mos), B-cell translocation gene (btg3), growth differentiation factor 9 ( $g d f 9)$, and mutS homolog 4 (msh4).

\section{Results}

\section{Zygote Arrest I (zarl)}

The nucleotide sequence of rainbow trout zar1 cDNA was 1195 bp in length (EU124662) and presumably encoded for a 333-aa protein. The encoded protein (ABV25059) had an estimated molecular mass of $38 \mathrm{kDa}$. The rainbow trout zar1 protein exhibited 64\%, 60\%, and $41 \%$ sequence identity with zebrafish (Danio rerio), Xenopus and Human zar1 proteins respectively (Figure 1) and the phylogenetic analysis showed that rainbow trout zar1 was orthologous to ZAR1 proteins previously characterized in vertebrates (Figure 2). As previously reported for other species, the zar1 rainbow trout sequence exhibited an atypical Plant Homeo Domain (PHD) finger in its C-terminal region (Figure 1). Real-time PCR data showed that zar1 was strongly expressed in the ovary (Figure 3A). The transcript was also present in unfertilized eggs thus demonstrating that trout zar1 is maternally-inherited. Finally, zar1 transcript could be detected in testis but not in any other tissue. In the ovary, in situ hybridization data showed that zar1 was expressed in previtellogenic oocytes (Figure 3A).

\section{v-mos Moloney murine sarcoma viral oncogene-like protein (mos)}

The nucleotide sequence of rainbow trout mos CDNA was 1530 bp in length (EU276588) and presumably encoded for a 335-aa protein. The encoded protein (ABX64430) had an estimated molecular mass of $37 \mathrm{kDa}$. The rainbow trout mos protein exhibited 62\%, 51\%, and $48 \%$ sequence identity with zebrafish, Xenopus and Human MOS proteins respectively (Figure 4). The phylogenetic analysis showed that rainbow trout mos was orthologous to previously characterized MOS proteins (Figure 5). Realtime PCR data showed that mos was strongly expressed in the ovary (Figure 3B). The transcript was also present in unfertilized eggs thus demonstrating that mos is maternally-inherited. Finally, mos transcript could not be detected in any other tissue. In the ovary, in situ hybridization data showed that mos was expressed in previtellogenic oocytes (Figure 3B).

\section{B-cell translocation gene (btg3)}

The nucleotide sequence of rainbow trout $b \operatorname{tg} 3$ was 1385 bp in length (EU723246) and presumably encoded for a 237 -aa protein. The encoded protein had an estimated molecular mass of $27 \mathrm{kDa}$. The rainbow trout btg 3 protein exhibited $64 \%$ and $48 \%$ sequence identity with a predicted zebrafish sequence and Human BTG3 protein respectively (Figure 6) and the phylogenic analysis showed that the rainbow trout btg3 was orthologous to BTG3 proteins previously characterized in vertebrates (Figure 7). Real-time PCR data showed that btg3 was strongly expressed in the ovary and in unfertilized eggs thus demonstrating that $b \operatorname{tg} 3$ is maternally-inherited (Figure $3 \mathrm{C}$ ). The transcript was also present at lower levels in testis, kidney, intestine, gills and brain. Finally, btg 3 transcript could be detected at extremely low levels in several other tissues but not in spleen. In the ovary, in situ hybridization data showed that $b \operatorname{tg} 3$ was expressed in the previtellogenic oocyte (Figure 3C).

\section{Growth differentiation factor 9 (gdf9)}

For gdf9, a partial rainbow trout cDNA (EU723245) was sequenced. The deduced rainbow trout gdf9 aa sequence exhibited $56 \%, 56 \%, 47 \%, 43 \%$ and $40 \%$ sequence identity with zebrafish, seabass, chicken, mouse and Human GDF9 proteins respectively (Figure 8) and the phylogenic analysis clearly showed that the rainbow trout gdf9 was orthologous to gdf9 proteins previously characterized in teleosts (Figure 9) [6,7]. In contrast, the topology of the tree vertebrates is not consistent with orthology relationships of GDF9 and BMP15 among vertebrates. This artifact could be due to a long-branch attraction 

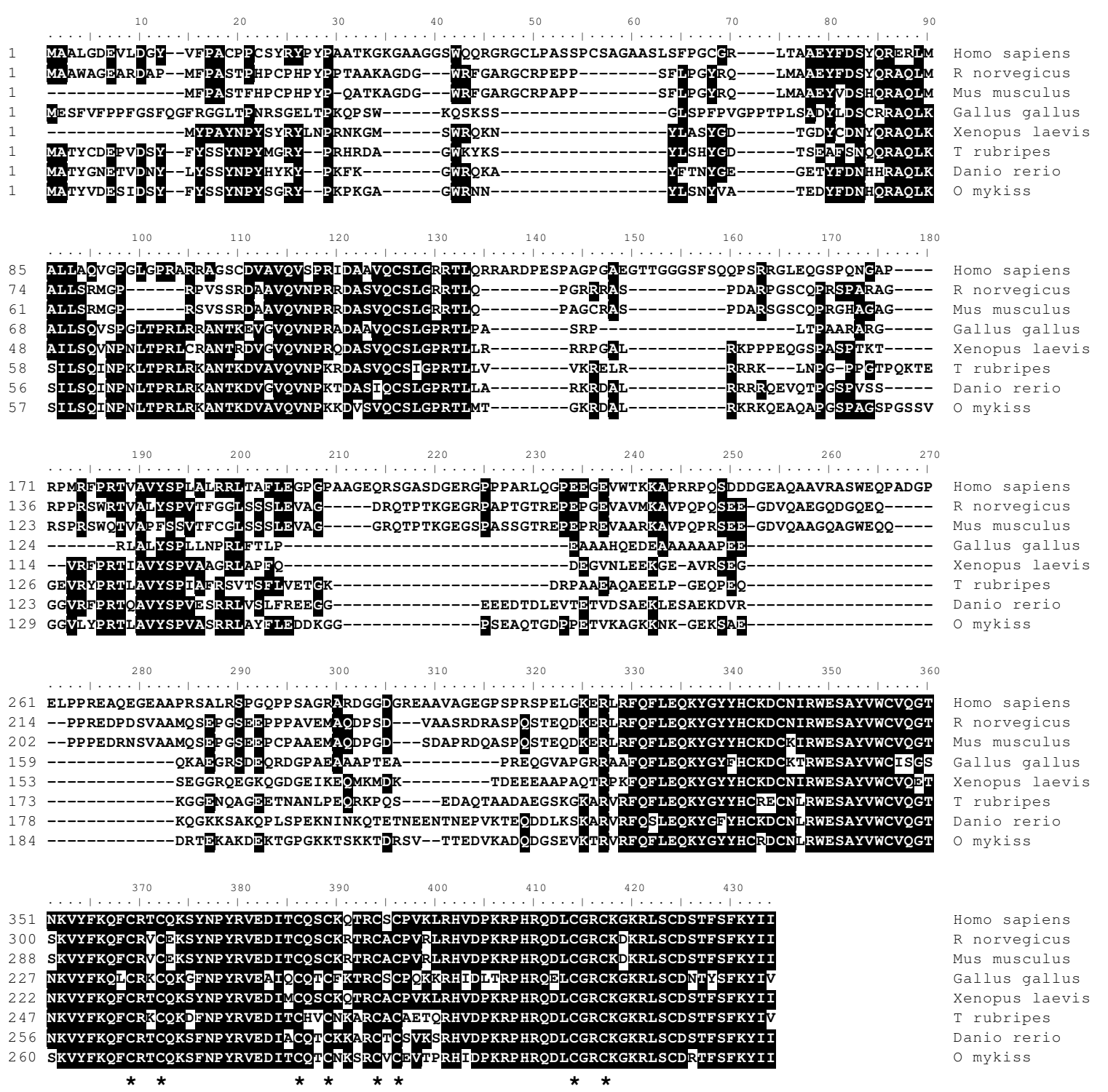

\section{Figure I}

Alignment of vertebrate ZARI amino acid sequences. Comparison of rainbow trout zarl amino acid sequence (ABV25059) with human (NP_7833 I8), mouse (NP_777366), rat (EDL89977), chicken (XP_00I234452), xenopus (NP_001083958), fugu (NP_001027939), and zebrafish (NP_919362) amino acid sequences. Shaded areas indicate identical amino acids. Asterisks denote the conserved cysteines of the atypical PHD motif.

phenomenon. Real-time PCR data showed that gdf9 was strongly expressed in the ovary (Figure 3D). The transcript was also present in unfertilized eggs thus demonstrating that $g d f 9$ is maternally-inherited. Finally, $g d f 9$ transcript could not be detected in any other tissue. In the ovary, in situ hybridization data showed that $g d f 9$ was expressed in previtellogenic oocytes (Figure 3D).

\section{mutS homolog 4 (msh4)}

For msh4, a partial rainbow trout cDNA (EU723247) was sequenced. The deduced rainbow trout msh4 aa sequence 


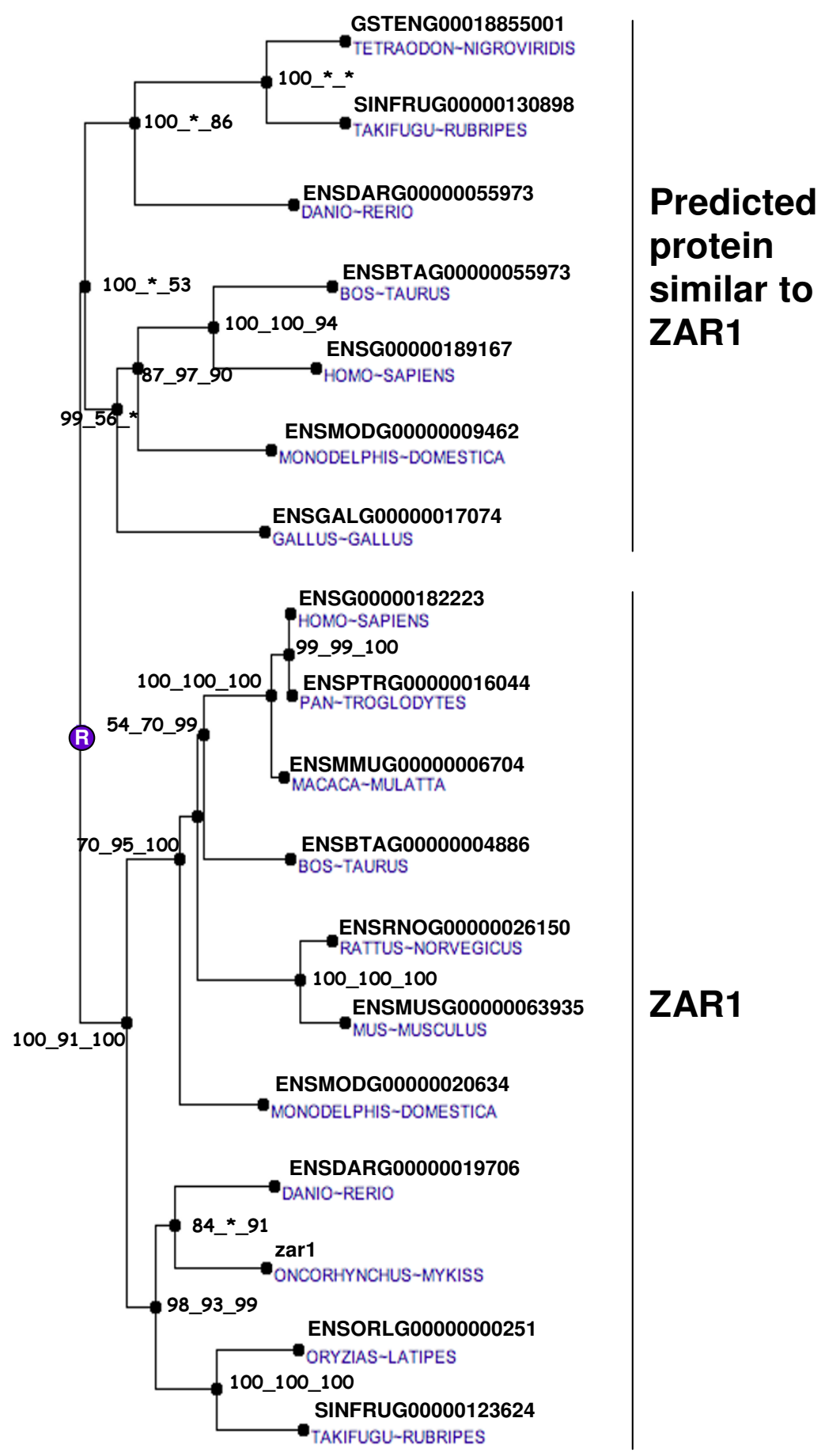

Figure 2

Phylogenetic tree of ZARI proteins. The phylogenetic tree was built from protein sequences using the Ensembl database. The tree is the fusion on the $\mathrm{NJ}$ topology, of three phylogenetic trees built based on neighbour joining, maximum parsimony, and maximum likelihood. For each node, bootstrap values are reported for each npl method. An asterisk indicates that the bootstrap value is lower than $50 \%$. Bootstrapping was carried out with 1000 replications. "R" node represents the ancestral gene. 

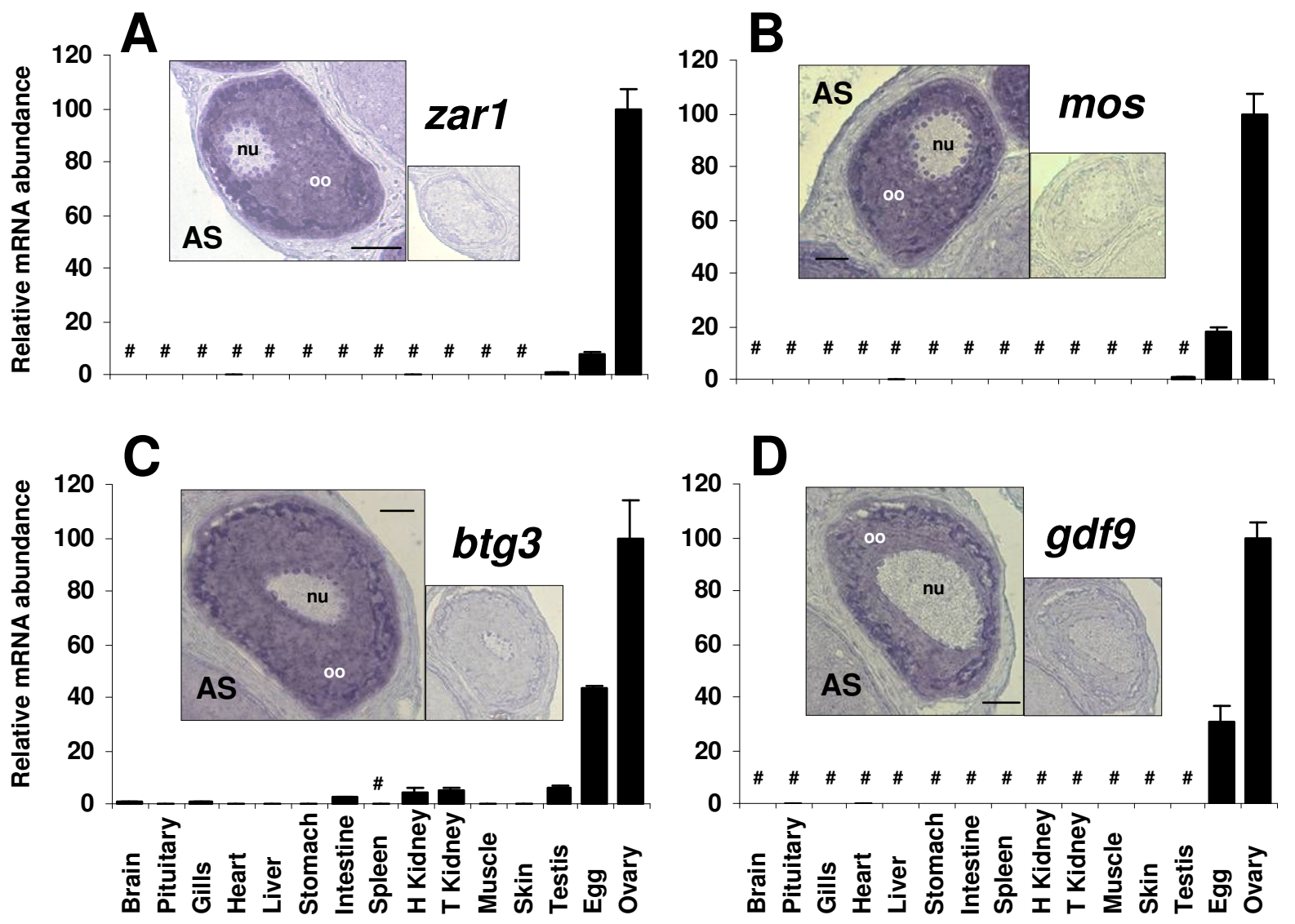

Figure 3

Tissue expression of rainbow trout zarl, mos, btg3 and gdf9. Tissue expression of rainbow trout zarl, mos, btg3 and gdf9 transcripts. Real-time PCR analysis was conducted using total RNA originating from the following tissues sampled in 3 different fish: brain, pituitary, gills, heart, liver, stomach, intestine, spleen, head kidney, trunk kidney, muscle, skin, ovary, unfertilized eggs (i.e. metaphase II oocytes), and stage II testis. For each tissue, 3 separate reverse transcription reactions were carried out using separate RNA samples originating from 3 different fish. Reverse transcription reactions were pooled and use to run real-time PCR in triplicates. Mean and standard deviation are shown $(\mathrm{N}=3)$. Expression levels not significantly different from background signal at $p<0.05$ are indicated (\#). Expression levels are expressed as a percentage of the expression in the ovary. In situ hybridization of rainbow trout ovarian tissue sections in the presence of antisense $(\mathrm{AS})$ probe. Labels: $\mathbf{n u}=$ nucleus, $\mathbf{0 o}=$ ooplasm. Bars represent $200 \mu \mathrm{m}$. A smaller view of an adjacent section hybridized with the sense probe is shown for each gene.

exhibited $66 \%$ and $67 \%$ sequence identity with mouse and Human MSH4 proteins respectively while it exhibited $81 \%$ with an aa sequence deduced from the zebrafish genome (Figure 10) and the phylogenic analysis showed that the rainbow trout msh4 was orthologous to MSH4 proteins previously characterized in vertebrates (Figure 11). Real-time PCR data showed that $m s h 4$ was strongly expressed in the ovary and in the testis (Figure 12). The transcript was also present at low but detectable levels in unfertilized eggs but could not be detected in any other tissue.

\section{Discussion}

\section{Zygote Arrest I (zarl)}

Zygote arrest 1 (Zar 1) is a maternal-effect gene critical for the oocyte-to-embryo transition first identified in the mouse [8]. In this species, zar1\% mice are infertile as most of their embryos stop developing at one-cell stage. Since its discovery, Zar1 was characterized and its expression studied in several vertebrates species including mammals [9-12], chicken [13] and Xenopus [12]. By contrast, available data in fish are scarce. Zebrafish (Danio rerio) and pufferfish (Fugu rubipres) zar1 sequences have been 

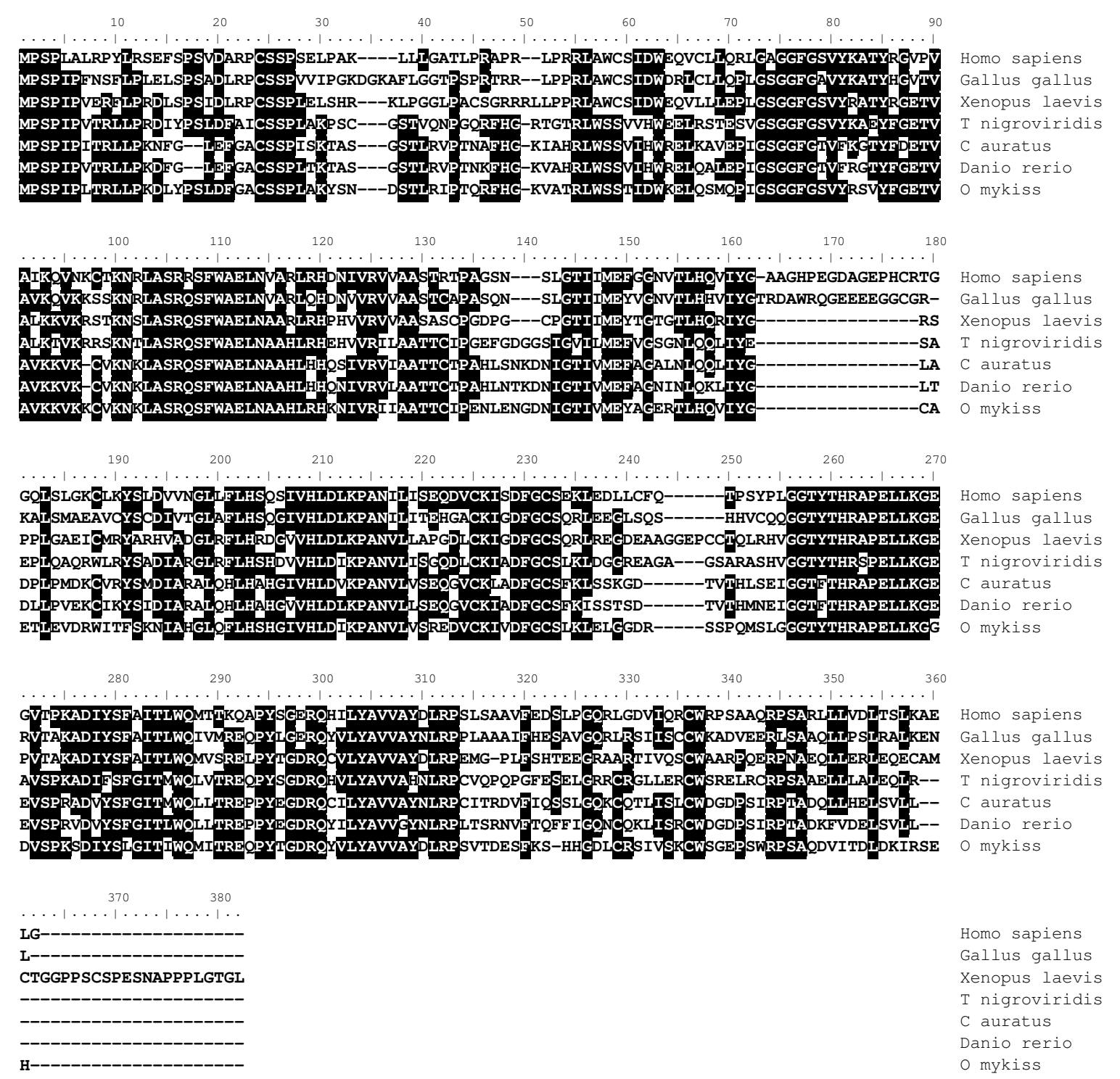
Homo sapiens Gallus gallus Xenopus laevis $\mathrm{T}$ nigroviridis C auratus Danio rerio o mykiss

\section{Figure 4}

Alignment of vertebrate MOS amino acid sequences. Comparison of rainbow trout mos amino acid sequence (ABX64430) with human (NP_005363), chicken (NP_001026687), xenopus (NP_00108I563), tetraodon (CAF92637), goldfish (BAA85880) and zebrafish (NP_99I I43) amino acid sequences.

reported but no information is available on tissue or cellular expression of zar1 in any fish species. Similarly to what has been reported in all studied vertebrate species [12], the rainbow trout zar1 sequence exhibits an atypical PHD motif (C-X $\left.2-\mathrm{C}-\mathrm{X}_{13}-\mathrm{C}-\mathrm{X}_{2}-\mathrm{C}-\mathrm{X}_{4}-\mathrm{C}-\mathrm{X}_{1}-\mathrm{C}-\mathrm{X}_{17}-\mathrm{C}-\mathrm{X}_{2}-\mathrm{C}\right)$ (Figure 1). The phylogenic analysis confirmed that the rainbow trout zar1 sequence was orthologous to the previously characterized vertebrate ZAR1 sequences includ- ing mouse Zar1 (Figure 2). We also show, for the first time in any fish species, that rainbow trout zar1 is strongly expressed in the ovary whereas a limited expression is observed in metaphase II oocytes (unfertilized eggs). Within the ovary, the expression was limited to the ooplasm as demonstrated by in situ hybridization. A very low signal was also observed in testis whereas no detectable expression was seen in any other tissue. In agreement 


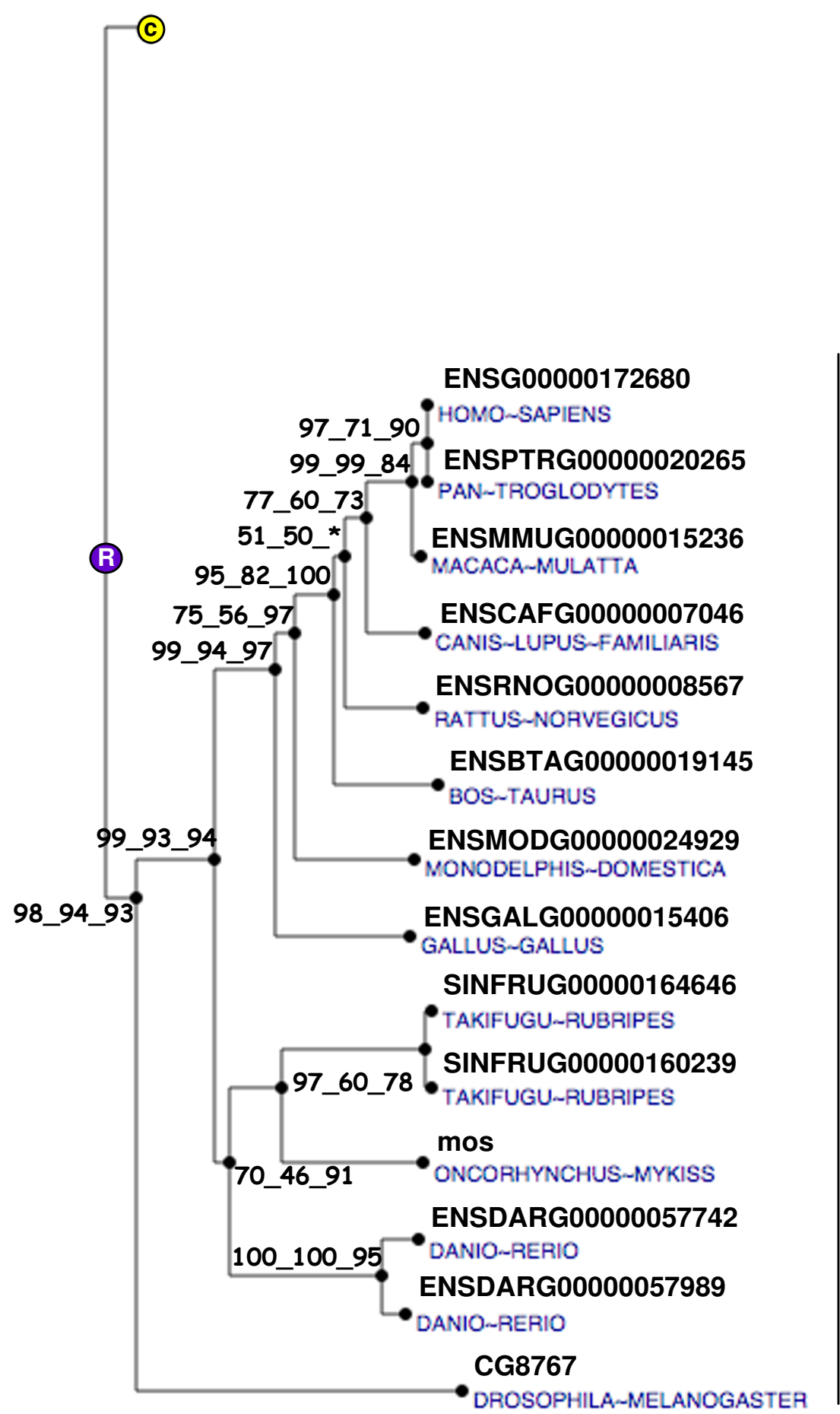

\section{MOS}

Figure 5

Phylogenetic tree of MOS proteins. The phylogenetic tree was built from protein sequences using the Ensembl database. The tree is the fusion on the $\mathrm{NJ}$ topology, of three phylogenetic trees built based on neighbour joining, maximum parsimony, and maximum likelihood. For each node, bootstrap values are reported for each npl method. An asterisk indicates that the bootstrap value is lower than $50 \%$. Bootstrapping was carried out with 1000 replications. "R" node represents the ancestral gene. For clarity reasons, the branch corresponding to paralogous genes were reduced and indicated by a circled $\mathrm{C}$. 


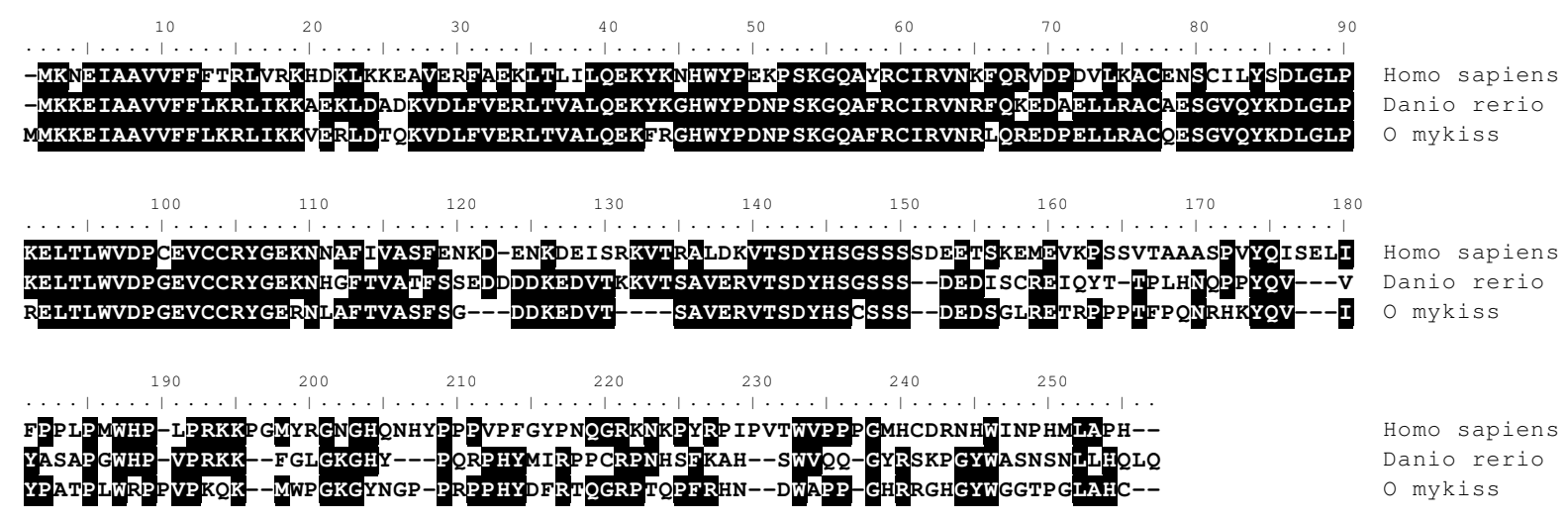

\section{Figure 6}

Alignment of vertebrate BTG3 amino acid sequences. Comparison of rainbow trout btg3 amino acid sequence (ACE74545) with human (NP_006797), and zebrafish (XP_707837) amino acid sequences.

with the results reported here, Zar1 was shown to be expressed exclusively in the oocyte in chicken and mouse $[8,12,13]$. In contrast, expression in other tissues such as testis [8,11], muscle [12], lung [12], and brain [11] was also observed in various vertebrates species. In bovine, pig and human, the mRNA expression observed in the testis results from an alternative splicing of the ZAR1 gene [11]. Together, rainbow trout zar1 sequence and tissue expression are consistent with a role in oocyte/embryo development in fish that would be similar to what has been shown in the mouse. Further studies are needed to thoroughly explore any relationship between zar1 expression in the oocyte and the acquisition of oocyte developmental competence.

\section{v-mos Moloney murine sarcoma viral oncogene-like protein (mos)}

In the mouse oocyte, Mos encodes for a serine-threonine kinase involved in the maintenance of the meiotic arrest at metaphase II [14-16]. A disruption of Mos results in spontaneous parthenogenetic activation of oocytes $[14,16]$. In Xenopus, mos has also long been implicated in the maintenance of the meiotic arrest [17]. In contrast, data on mos function and expression are extremely limited in fish. In the goldfish (Carassius auratus), mos is also involved in the metaphase II arrest but does not participates in oocyte maturation [18]. In the present study, we observed that rainbow trout mos mRNA is specifically expressed in the oocyte and not detected in any other tissue. Interestingly, mos mRNA is present in the unfertilized egg and is therefore maternally inherited. To the best of our knowledge, no information is available on the tissue distribution of the mos mRNA in fish. In several mammalian species, Mos mRNA was only found in embryos, ovary and testis $[19,20]$. In addition, mos mRNA was found to be expressed in the shark testis [21]. While it is unknown if rainbow trout mos is expressed in the testis at other stages, its expression in the oocyte is consistent with existing data in higher vertebrates. Interestingly, the expression of mos mRNA in the unfertilized egg suggests that mos could participate in early development in addition to its well documented role in meiotic arrest.

\section{B-cell translocation gene (btg3)}

BTG3 also named ANA and TOB5 belongs to a family of proteins, the BTG family; know for their anti-poliferative activity. In this family, 6 different proteins have been characterized in vertebrates [22]. The phylogenetic analysis carried out in the present study clearly shows that we have identified the rainbow trout btg3 cDNA. The Btg3 gene was originally cloned in the mouse [23] and reported to be expressed in several cell lines and in a wide variety of murine and human adult tissues [23,24]. Similarly, porcine Btg3 mRNA was detected in most tissues assayed [25]. In the present study, btg3 mRNA could be detected in many tissues at very low levels. However, a strong and predominant expression was monitored in the oocyte. Together, our observations are consistent with existing data in mammals. However the oocyte-predominant expression of BTG3 was never reported in any vertebrate species and a thorough expression analysis will be necessary in other vertebrate species. Interestingly, several studies have shown that BTG4, another BTG family member, was preferentially expressed in the chicken oocyte [13] 


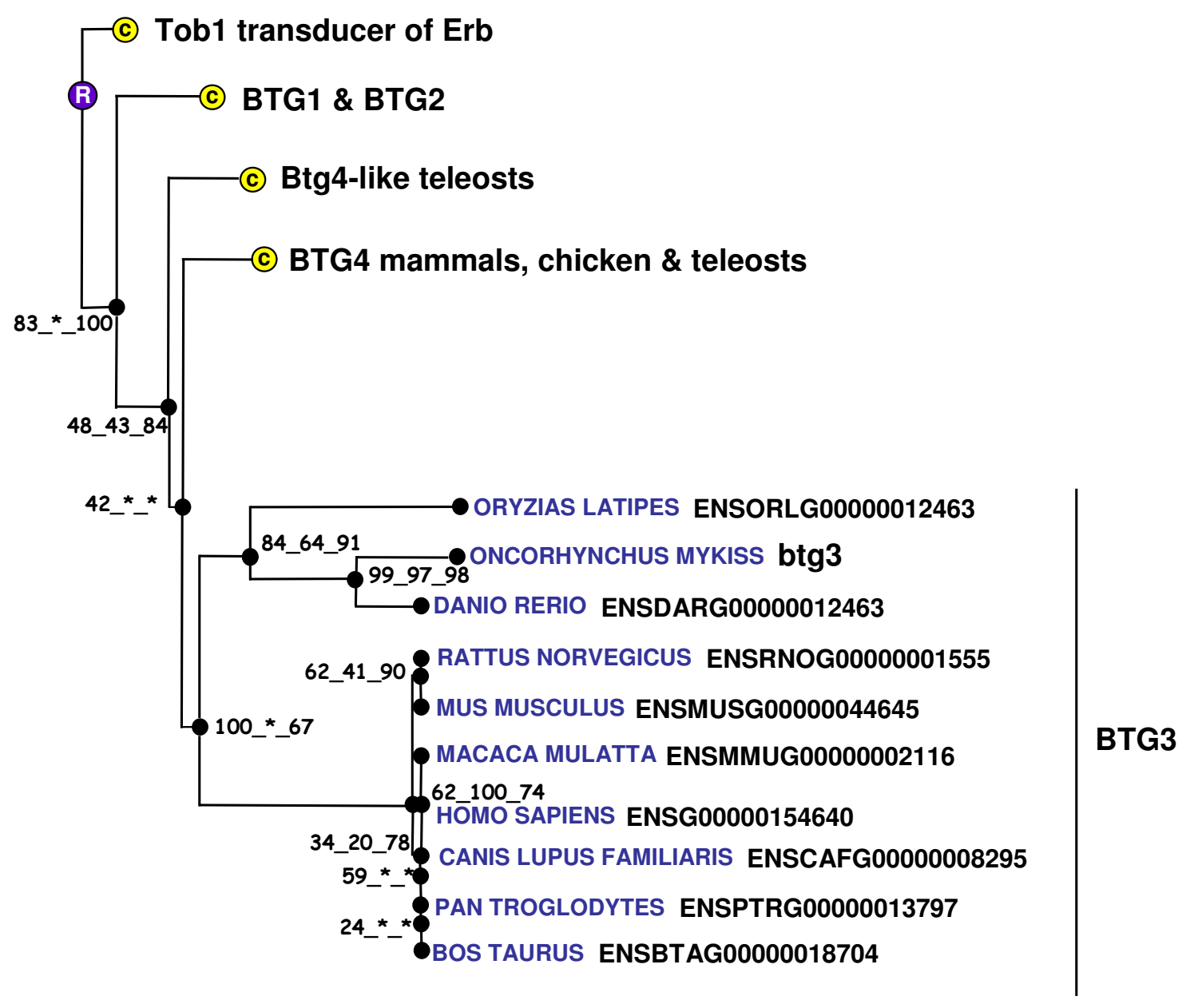

Figure 7

Phylogenetic tree of BTG3 proteins. The phylogenetic tree was built from protein sequences using the Ensembl database. The tree is the fusion on the NJ topology, of three phylogenetic trees built based on neighbour joining, maximum parsimony, and maximum likelihood. For each node, bootstrap values are reported for each npl method. An asterisk indicates that the bootstrap value is lower than $50 \%$. Bootstrapping was carried out with 1000 replications. "R" node represents the ancestral gene. For clarity reasons, the branches corresponding to paralogous genes were reduced and indicated by a circled $\mathrm{C}$.

and in bovine reproductive tissues [26]. In fish, a recent transcriptomic study also revealed that btg 4 was predominantly expressed in zebrafish ovarian tissue [5].

In the mouse, the $30 \mathrm{kDa}$ protein encoded by the Btg3 gene was cell cycle-dependent and peaked at the end of the G1 phase [23]. Overexpression of the human cognate protein resulted in an impaired serum-induced cell cycle progression from the G0/G1 to S phase in NIH3T3 cells [24]. More recently, in an attempt to study DNA damagedinduced genes, BTG3 was identified as a p53 target exhibiting an antiproliferative activity. Together, the predominant oocyte-expression of rainbow trout btg3 and the antiproliferative activity of the cognate protein in mammals suggest that btg3 could play an important role in oocyte development in fish. In addition, the presence of btg3 mRNA in the trout female gamete suggests a role for btg3 during early embryonic development, possibly in response to UV-induced DNA damage.

\section{Growth differentiation factor 9 (gdf9)}

Gdf9 is an oocyte-specific gene of the TGF beta superfamily involved in folliculogenesis. It participates in the successful transition from primary to secondary follicles and it was previously shown that $G d f 9$-null mice are sterile $[27,28]$. In fish, gdf9 was very recently characterized in 


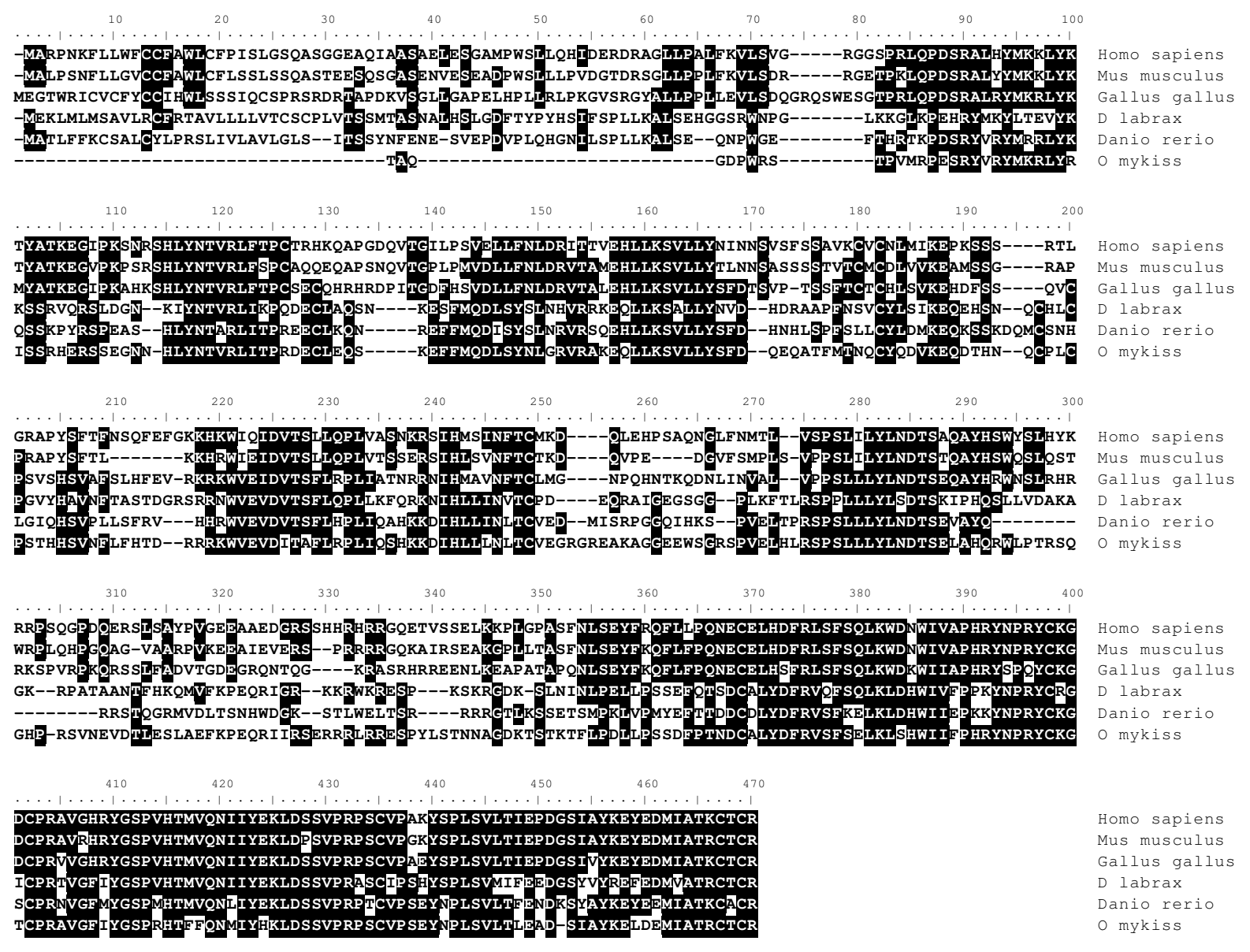

Figure 8

Alignment of GDF9 amino acid sequences in vertebrates. Comparison of rainbow trout gdf9 amino acid sequence (ACE74544) with seabass (CAP7I884), zebrafish (NP_00I0I2383), chicken (AAT74587), mouse (NP_032I36) and human (NP_00525I) GDF9 proteins.

zebrafish [7] and sea bass (Dicentrarchus labrax) [6]. In the present study, the phylogenic analysis clearly showed that rainbow trout gdf9 was orthologous to those previously characterized gdf9 proteins in teleosts [6,7] despite the difficulty to construct a reliable phylogenetic tree among vertebrate species. Northern blot analysis showed an ovarian-specific expression of gdf9 in sea bass [6]. Similarly, semi quantitative PCR showed a gdf9 expression in zebrafish oocyte and testis, and possibly a weak signal in follicular cells [7]. In the present study, we clearly showed using real-time PCR and in situ hybridization that rainbow trout $g d f 9$ is exclusively expressed in the oocyte. Interestingly, significant levels of $g d f 9$ mRNA were detected in the unfertilized egg, thus demonstrating that gdf9 is maternally inherited in rainbow trout. This observation is sup- ported by semi-quantitative PCR data in zebrafish showing strong mRNA levels at early blastula stage and sharp decrease during gastrulation [7]. While data on $g d f 9$ in fish are scarce, the observed expression patterns are consistent with existing data in mammals. However, the functions of gdf9 in fish, including a possible role during early development, remain currently unknown.

\section{mutS homolog 4 (msh4)}

mutS homolog 4 (MSH4) is a meiosis-specific gene belonging to the DNA mismatch repair (MMR) system. In yeast (Saccharomyces cerevisiae) MSH4 is required for reciprocal recombination and proper segregation of homologous chromosomes during meiosis I [29]. In humans, $\mathrm{MSH} 4$ protein is only found in testis and ovary [30]. In 


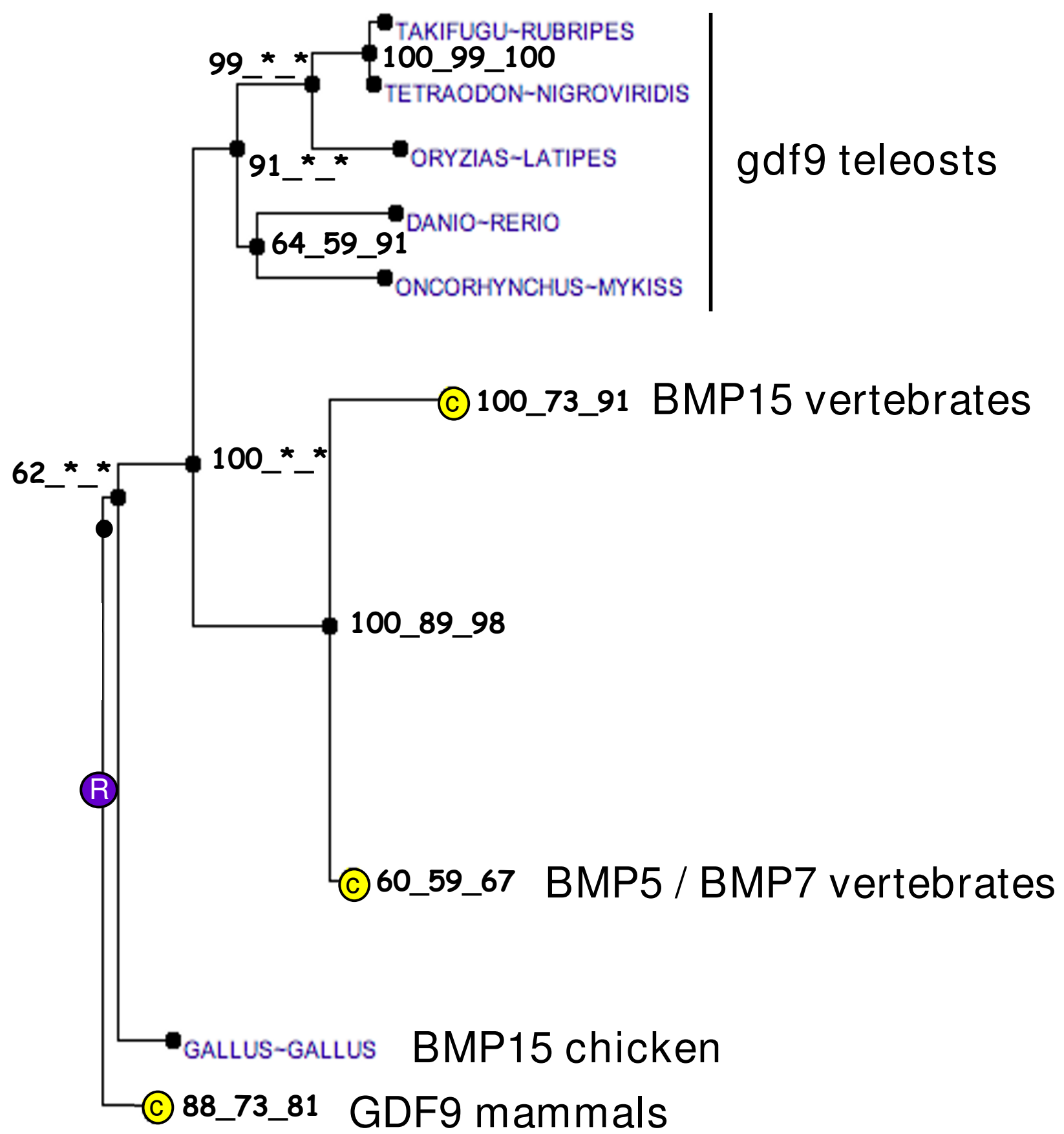

Figure 9

Phylogenetic tree of GDF9 proteins. The phylogenetic tree was built from protein sequences using the Ensembl database. The tree is the fusion on the $\mathrm{NJ}$ topology, of three phylogenetic trees built based on neighbour joining, maximum parsimony, and maximum likelihood. For each node, bootstrap values are reported for each npl method. An asterisk indicates that the bootstrap value is lower than $50 \%$. Bootstrapping was carried out with 1000 replications. "R" node represents the ancestral gene. For clarity reasons, some of the branches corresponding to paralogous genes or orthologous genes in higher vertebrates were reduced and indicated by a circled $\mathrm{C}$. 


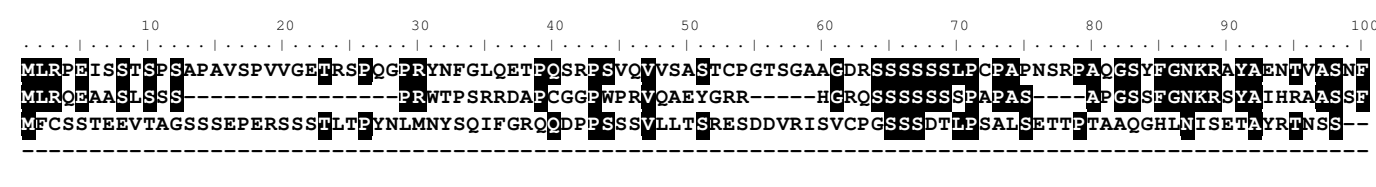

Homo sapiens
Mus musculus Mus musculus
Danio rerio o mykiss
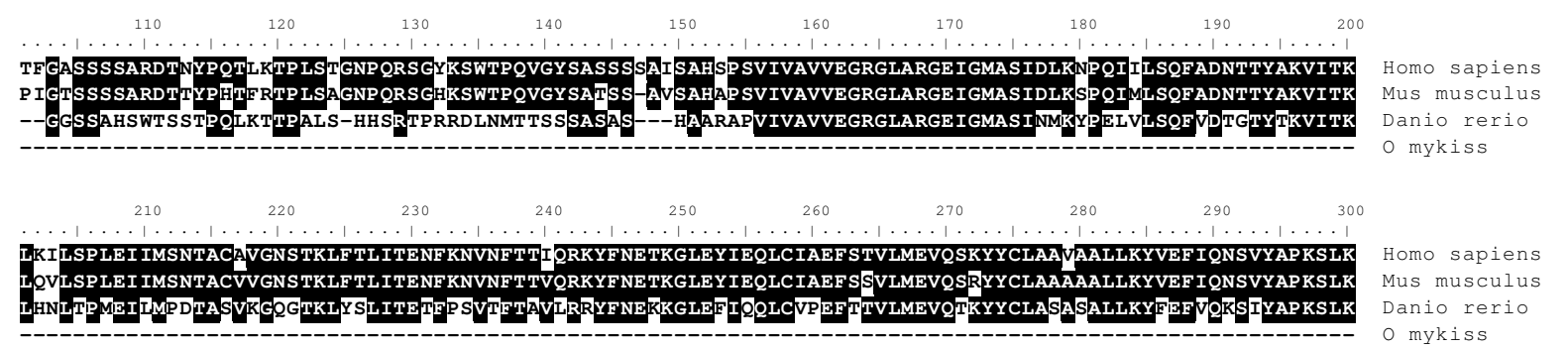
Homo sapiens Mus musculus Danio rerio o mykiss

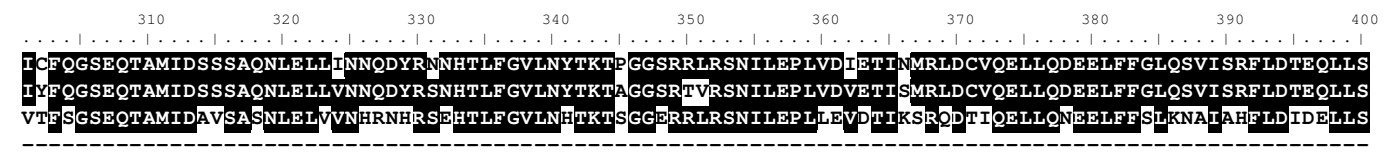

Homo sapiens Mus musculus Danio rerio o mykiss

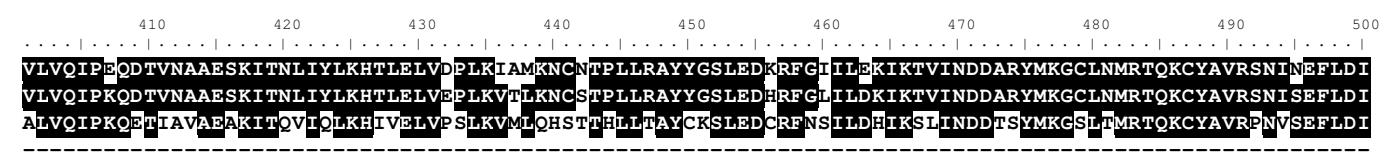
Homo sapiens Mus musculus Danio rerio o mykiss

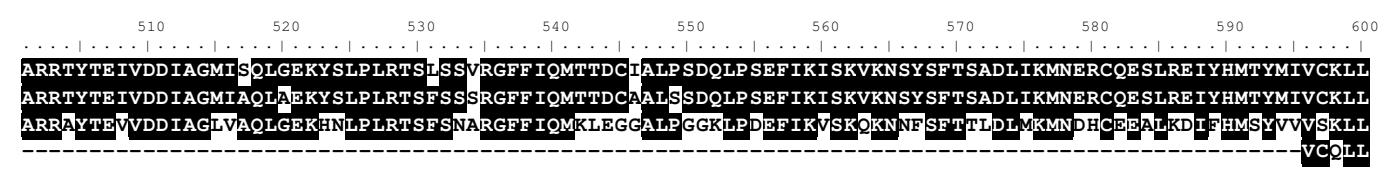
Homo sapiens Mus musculus Danio rerio o mykiss

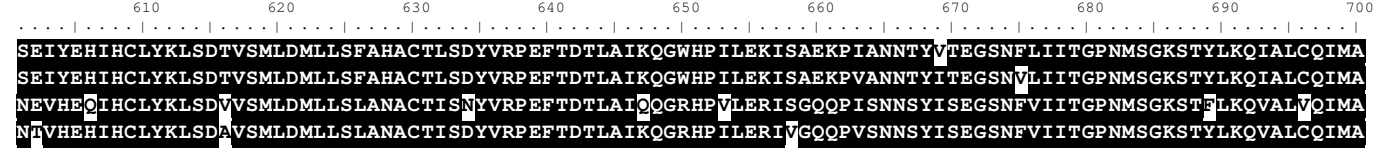

Homo sapiens Mus musculus Danio rerio o mykiss

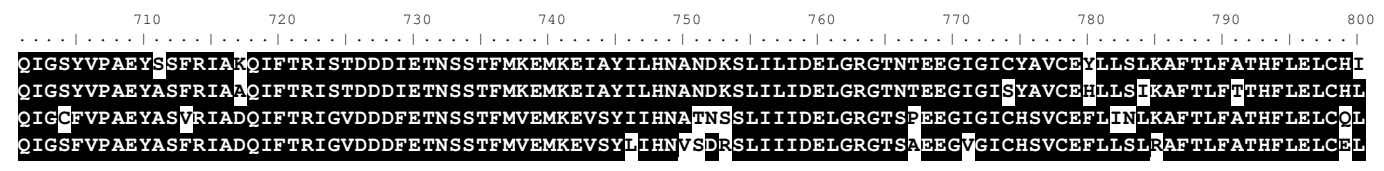
Homo sapiens
Mus musculus
Danio rerio
O mykiss

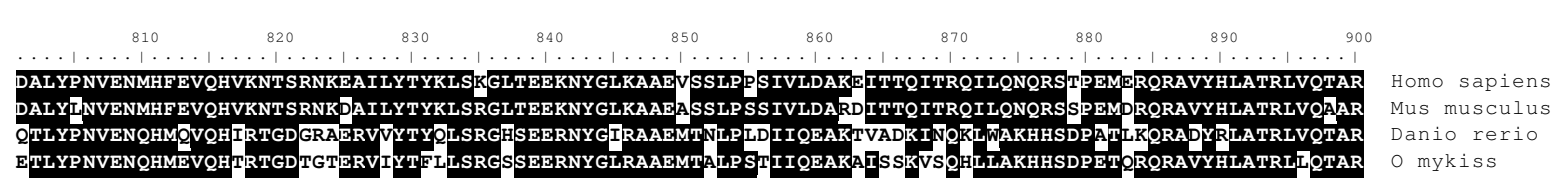

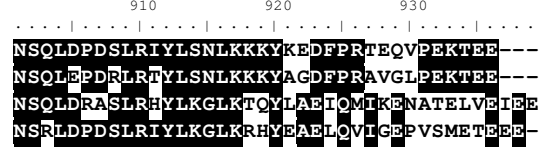

Homo sapiens
Mus musculus
Danio rerio
O mykiss

Figure 10

Alignment of MSH4 amino acid sequences in vertebrates. Comparison of rainbow trout msh4 amino acid sequence (ACE74546) with zebrafish (XP_688406), mouse (AALI8350), and human (AAB72039) MSH4 proteins. 


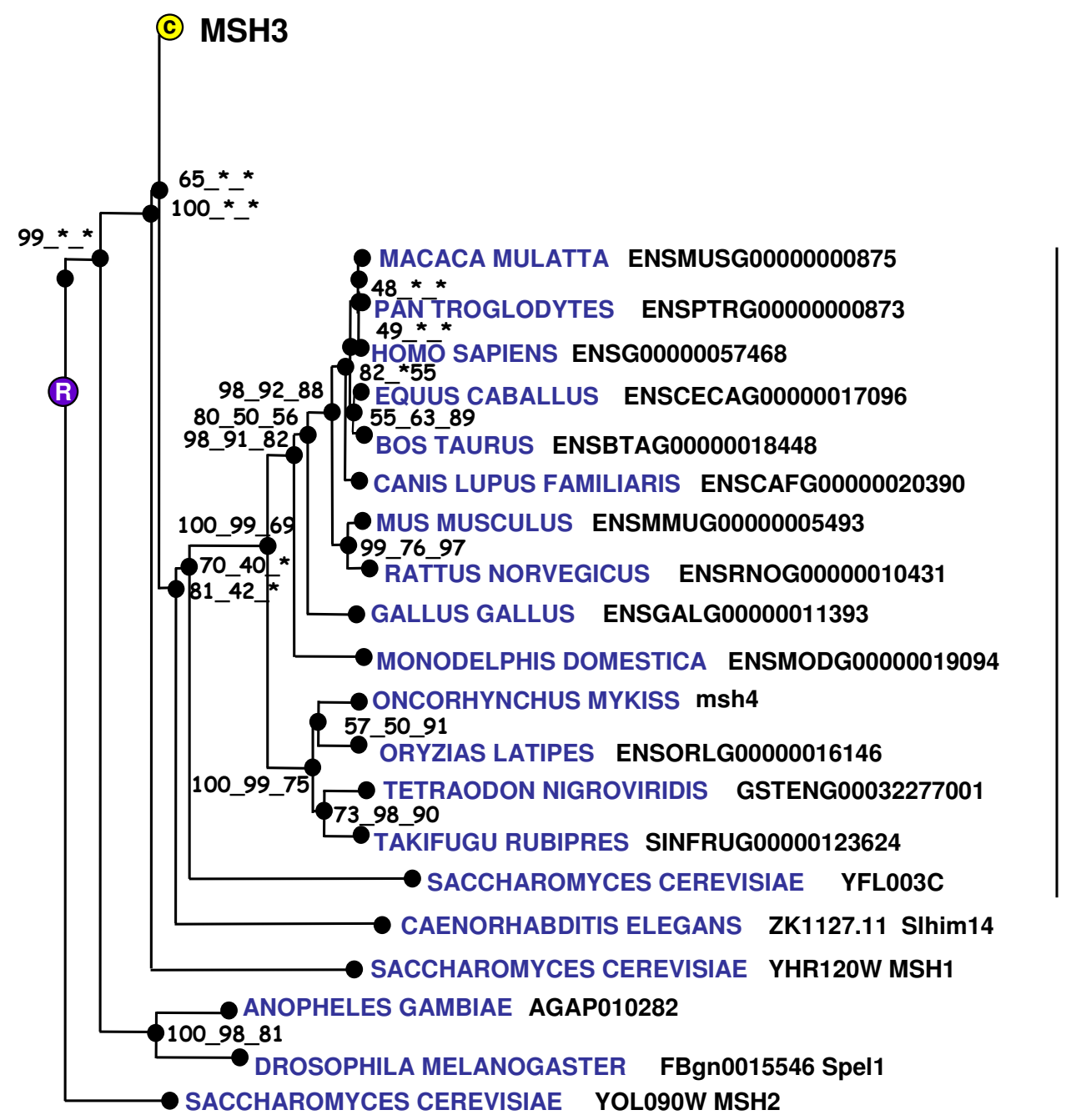

MSH4

Figure I I

Phylogenic tree of MSH4 proteins. The phylogenetic tree was built from protein sequences using the Ensembl database. The tree is the fusion on the $\mathrm{NJ}$ topology, of three phylogenetic trees built based on neighbour joining, maximum parsimony, and maximum likelihood. For each node, bootstrap values are reported for each npl method. An asterisk indicates that the bootstrap value is lower than $50 \%$. Bootstrapping was carried out with 1000 replications. "R" node represents the ancestral gene. For clarity reasons, the branch corresponding to $\mathrm{MSH} 3$ paralogous genes was reduced and indicated by a circled $\mathrm{C}$.

mice, Msh4 plays an essential role in the control of meiotic recombination and a disruption of this gene leads to male and female sterility due to meiotic failure [31]. In fish, very little is known about msh4. To date, msh4 cDNA and protein sequences were never characterized from any fish species and only sequences automatically predicted from zebrafish and tetraodon genomes are available. In rainbow trout, in agreement with existing data in mammals, the tissue distribution study shows a gonad-specific expression pattern and a strong testicular expression. In addition, high expression levels were found in the late vitellogenic ovary, immediately prior to meiosis resumption. Based on existing data in yeast and mammals, it can be speculated that msh4 plays an important role in meiosis in fish. However, the msh 4 mRNA is also detected in metaphase II oocytes at low levels. This indicates that msh4 mRNA is maternally inherited and could thus participate in early development, possibly through DNA mis- 


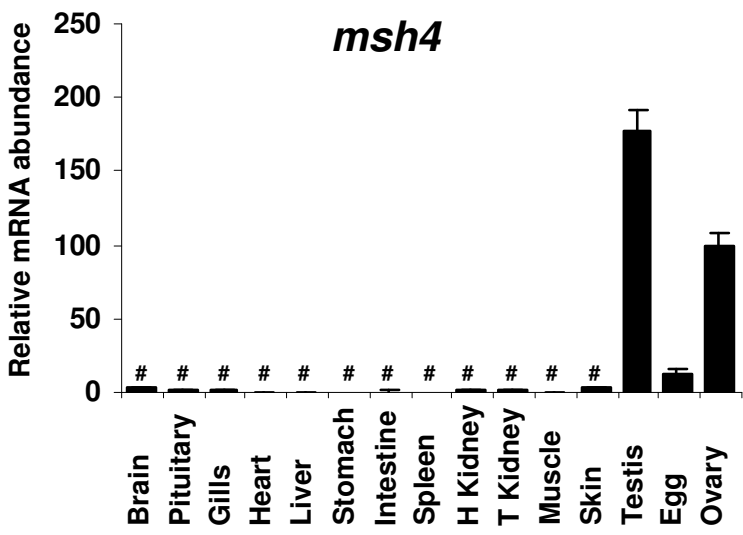

Figure 12

Tissue expression of rainbow trout msh4. Tissue expression of rainbow trout msh4 transcript. Real-time PCR analysis was conducted using total RNA originating from the following tissues sampled in 3 different fish: brain, pituitary, gills, heart, liver, stomach, intestine, spleen, head kidney, trunk kidney, muscle, skin, ovary, unfertilized eggs, and stage II testis. For each tissue, 3 separate reverse transcription reactions were carried out using separate RNA samples originating from 3 different fish. Reverse transcription reactions were pooled and use to run real-time PCR in triplicates. Mean and standard deviation are shown $(\mathrm{N}=3)$. Expression levels not significantly different from background signal at $\mathrm{p}<$ 0.05 are indicated (\#). Expression levels are expressed as a percentage of the expression in the ovary.

match repair functions. Further investigations are needed to study the expression of msh4 in fish and characterize its participation in oocyte and embryo development.

\section{Conclusion}

Using an in silico analysis, we have successfully identified 5 previously uncharacterized rainbow trout $\mathrm{CDNAs}$ exhibiting an oocyte-specific, gonad-specific, or oocyte-predominant expression. Among those 5 genes, 3 had never been characterized in any fish species. In addition, we report the oocyte-predominant expression of btg 3 for the first time in any vertebrate species. Finally, expression patterns of those 5 genes in fish and the functions of their orthologs in higher vertebrates strongly suggest that they might play an important role in fish oocyte development, meiotic arrest and early embryonic development.

\section{Methods \\ In silico identification of candidate genes specifically expressed in the oocyte}

A differential digital display (DDD) analysis was previously performed with mouse ESTs providing a list of murine oocyte-specific genes [32]. Cognate rainbow trout expressed sequence tags (ESTs) were subsequently identi- fied using a reciprocal blast search strategy. A tblastX search was performed against all rainbow trout expressed sequence tags (ESTs) available in dbEST [33] using oocytespecific mouse sequences identified in silico. The corresponding clones were obtained from INRA-Agenae program resource center (Jouy-en-Josas, France) [34] and fully sequenced in both directions using the dye-termination method (ABI PRISM 310, PE Biosystems). The deduced amino acid sequence was used for sequence alignment and phylogenetic analysis. Alternatively, the amino acid sequence was deduced from rainbow trout ESTs belonging to the same UniGene cluster.

\section{Phylogenetic analysis}

Phylogenetic analysis was performed using the phylogenomic analysis pipeline available in the FIGENIX platform http://www.up.univ-mrs.fr/evol/figenix/[35]. FIGENIX retrieved sequences, provided multiple sequence alignments, performed phylogenetic reconstruction, and deduced orthology and paralogy relationships (for a detailed description of pipelines and models used, see [35]). For each studied gene, the protein sequence was entered in the phylogenomic inference task, which was run with the default parameters and with Ensembl database (release 49) [36]. We chose the NJ (neighbor joining) topology for the graphical representation. The trees (npl) are the fusion of three phylogenetic trees built based on neighbor joining [37], maximum parsimony, and maximum likelihood [38]. The Dayhoff PAM matrix provided the distance matrix for the NJ method. The evolutionary distance separating sequences is defined as the number of mutational events per site underlying the evolutionary history separating sequences. Thus, evolutionary relations among sequences are represented by the tree structure, where branch length represents the evolutionary distance $[38,39]$. Thus, evolutionary relations among sequences are represented by the tree structure, where branch length represents the evolutionary distance $[38,39]$. In phylogenetic tree, bootstrap values are reported on each node for each npl method. Bootstrapping was carried out with 1000 replications.

\section{Tissue collection and RNA extraction}

Investigations were conducted according to the guiding principles for the use and care of laboratory animals and in compliance with French and European regulations on animal welfare. Rainbow trout (Oncorhynchus mykiss) in their first reproductive season were obtained from an experimental fish farm (PEIMA, Sizun, France). Fish were deeply anaesthetized in 2-phenoxyethanol $(10 \mathrm{mg} / \mathrm{ml}$ of water), killed by a blow on the head and bled by gill arch section. Tissues were sampled from 3 ovulated females. Testis samples were obtained from 3 different males at stage II of spermatogenesis [40]. For RNA extraction, tissues were homogenized in Tri-reagent (Molecular 
Research Center, Cincinnati, OH) at a ratio of $100 \mathrm{mg}$ per $\mathrm{ml}$ of reagent and total RNA was extracted according to manufacturer's instruction. For in situ hybridization, ovarian tissue was sampled from an ovulated female, fixed in Dietrick's fixative (10\% Formaldehyde, 28. 5\% ethanol, $2 \%$ glacial acetic acid) at $4{ }^{\circ} \mathrm{C}$ overnight, rinsed in tap water for 1 hour and held in 50\% ethanol until further processing.

\section{Real-time PCR}

Real-time PCR was performed using an I-Cycler IQ (Biorad, Hercules, CA) as previously described [41]. Reverse transcription products were diluted to $1 / 50$ and $5 \mu \mathrm{l}$ were used for each real-time PCR reaction. Triplicates were run for each RT product. Real-time PCR was performed using a real-time PCR kit provided with a SYBR Green fluorophore (Eurogentec, Belgium) according to the manufacturer's instructions and using $600 \mathrm{nM}$ of each primer (Table 1). After a $2 \mathrm{~min}$ incubation step at $50^{\circ} \mathrm{C}$ and a 10 min incubation step at $95^{\circ} \mathrm{C}$, the amplification was performed using the following cycle: $95^{\circ} \mathrm{C}, 20 \mathrm{sec} ; 62^{\circ} \mathrm{C}, 1$ min, 40 times. The relative abundance of target cDNA within sample set was calculated from a serially diluted ovarian cDNA pool using the I-Cycler IQ software. Subsequently, real-time PCR data were normalized using $18 \mathrm{~S}$ transcript abundance. After amplification, a fusion curve was obtained in order to ensure that a single PCR product had been generated using the following protocol: $10 \mathrm{sec}$ holding followed by a $0.5^{\circ} \mathrm{C}$ increase, repeated 80 times and starting at $55^{\circ} \mathrm{C}$.

\section{In situ hybridization}

Dehydration (increasing ethanol: $15 \mathrm{~min}$ in $50 \%$ ethanol, twice $15 \mathrm{~min}$ in $70 \%$ ethanol, $15 \mathrm{~min}$ in $80 \%$ ethanol, 30 min in 96\% ethanol, and $30 \mathrm{~min}$ in $96 \%$ ethanol/butanol $\mathrm{vol} / \mathrm{vol}$ ), clearing (butanol once for $30 \mathrm{~min}$, and twice for $3 \mathrm{~h}$ each), and paraffin infiltration (once for $1 \mathrm{~h}$ and twice for $2 \mathrm{~h}$, at $60^{\circ} \mathrm{C}$ ) were performed in a Citadel 1000 tissue processor (Shandon, Pittsburgh, PA). Dehydrated tissues were embedded in plastic molds in paraffin using a HistoEmbedder (TBS88, Medite, Germany).
Digoxigenin-labeled anti-sense RNA probes were produced using the Promega T3/T7 RNA polymerase Riboprobe Combination System as recommended by the manufacturer, using as DNA template a PCR product obtained following amplification of the plasmid inserts with $\mathrm{M} 13$ reverse and M13 forward primers. Digoxigeninlabeled riboprobes were then purified by precipitation in ammonium acetate $7.5 \mathrm{M}$ /ethanol for 2 hours at $-20^{\circ} \mathrm{C}$, and RNA concentrations were measured using a NanoDrop $^{\circledast}$ spectrophotometer. Serial cross-sections of $5 \mu \mathrm{m}$ were deparaffinized, re-hydrated in TBS (50 mM Tris, $\mathrm{pH}$ $7.4,150 \mathrm{mM} \mathrm{NaCl}$ ) and post-fixed in $4 \%$ PFA for $20 \mathrm{~min}$. ISH was performed using the "In situ Pro, Intavis AG robotic station". Incubation volumes for all ISH steps were set to $250 \mu \mathrm{l}$. Digestion was carried out for $20 \mathrm{~min}$ with $3 \mu \mathrm{g} / \mathrm{ml}$ of proteinase K. Pre-hybridization $(2 \mathrm{~h}$, $\left.60^{\circ} \mathrm{C}\right)$ and hybridization $\left(12 \mathrm{~h}, 60^{\circ} \mathrm{C}\right)$ were carried out in $50 \%$ formamide, $2 \times$ SSC, $1 \times$ Denhardt, $10 \%$ dextran sulfate, and $250 \mu \mathrm{g} / \mathrm{ml}$ tRNA. For hybridization the digoxigenin-labeled anti-sense RNA probes were diluted in hybridization buffer at a final concentration of $3 \mathrm{ng} / \mu \mathrm{l}$. Washing steps $(2 \times \mathrm{SSC}, 60 \mathrm{~min})$ were performed at $60^{\circ} \mathrm{C}$ followed by an RNAse treatment at $37^{\circ} \mathrm{C}$. The digoxigenin signal was then revealed with an anti-digoxigenin antibody conjugated with alkaline phosphatase (Roche Diagnostics Corp.) and a NBT/BCIP revelation system (Roche Diagnostics Corp.) as recommended by the manufacturer. Slides were mounted with mowiol 4-88 (Calbiochem).

\section{Authors' contributions}

TN performed RNA extraction, quantitative PCR analysis and sequencing and participated in the writing of the manuscript. SM carried out the in situ hybridization analysis and participated in the writing of the manuscript. PM carried out the phylogenetic analyzes and participated in the design of the study and the writing of the manuscript. JB coordinated the study, carried out the gene sequence analysis and drafted the manuscript. All authors read and approved the manuscript.

\section{Acknowledgements}

Supported by an INRA Animal Physiology and Livestock Systems department grant to PM and JB.

Table I: Real-time PCR primers

\begin{tabular}{|c|c|c|c|}
\hline Name & Acc \# & Forward primer & Reverse primer \\
\hline zarl & EUI 24662 & GAACGAGCAAGGTCTACTTCAAG & GCAAGTCTGGCAGGTGATGTC \\
\hline mos & $\overline{\text { EU276588 }}$ & GGCGACAGGCAATATGTTTT & CACTTGGACACAATGGATCG \\
\hline$g d f 9$ & EU723245 & ACGAGCGACTGTGCTTTGTAC & AATGATCCAATGGCTCAGTT \\
\hline btg 3 & EU723246 & AGAGGAGGTGTGCTGCAGAT & CGTCTGAGGAGGAACAGGAG \\
\hline msh4 & $\overline{\text { EU723247 }}$ & TCTGTCTGCGAATTCCTCCT & ACCTCCATGTGCTGGTTTTC \\
\hline 185 & AF308735 & CGGAGGTTCGAAGACGATCA & TCGCTAGTTGGCATCGTTTAT \\
\hline
\end{tabular}

For all studied genes the GenBank accession number of the rainbow trout cDNA and the sequence of the primers used for the real-time PCR study are shown 


\section{References}

I. Bonnet E, Fostier A, Bobe J: Microarray-based analysis of fish egg quality after natural or controlled ovulation. BMC Genomics 2007, 8:55

2. Acevedo N, Smith GD: Oocyte-specific gene signaling and its regulation of mammalian reproductive potential. Front Biosc 2005, 1 0:2335-2345

3. Dean J: Oocyte-specific genes regulate follicle formation, fertility and early mouse development. J Reprod Immunol 2002, 53: $17 \mid-180$

4. Zheng $P$, Dean J: Oocyte-specific genes affect folliculogenesis, fertilization, and early development. Semin Reprod Med 2007 25:243-25I.

5. Sreenivasan R, Cai M, Bartfai R, Wang X, Christoffels A, Orban L: Transcriptomic analyses reveal novel genes with sexually dimorphic expression in the zebrafish gonad and brain. PLOS ONE 2008, 3: el79|.

6. Halm S, Ibanez AJ, Tyler CR, Prat F: Molecular characterisation of growth differentiation factor 9 (gdf9) and bone morphogenetic protein I5 (bmp I5) and their patterns of gene expression during the ovarian reproductive cycle in the European sea bass. Mol Cell Endocrinol 2008.

7. Liu L, Ge W: Growth differentiation factor 9 and its spatiotemporal expression and regulation in the zebrafish ovary. Biol Reprod 2007, 76:294-302.

8. Wu X, Viveiros MM, Eppig JJ, Bai Y, Fitzpatrick SL, Matzuk MM Zygote arrest I (Zarl) is a novel maternal-effect gene critical for the oocyte-to-embryo transition. Nat Genet 2003, 33:|87-19|.

9. Brevini TA, Cillo F, Colleoni S, Lazzari G, Galli C, Gandolfi F: Expression pattern of the maternal factor zygote arrest I (ZarI) in bovine tissues, oocytes, and embryos. Mol Reprod Dev 2004 69:375-380.

10. Pennetier S, Uzbekova S, Perreau C, Papillier P, Mermillod P, DalbiesTran R: Spatio-temporal expression of the germ cell marker genes MATER, ZARI, GDF9, BMPI5, and VASA in adult bovine tissues, oocytes, and preimplantation embryos. Biol Reprod 2004, 71:1359-1366.

II. Uzbekova S, Roy-Sabau M, Dalbies-Tran R, Perreau C, Papillier P, Mompart F, Thelie A, Pennetier S, Cognie J, Cadoret V, Royere D Monget $\mathrm{P}$, Mermillod $\mathrm{P}$ : Zygote arrest I gene in pig, cattle and human: evidence of different transcript variants in male and female germ cells. Reprod Biol Endocrinol 2006, 4: I2

12. Wu X, Wang P, Brown CA, Zilinski CA, Matzuk MM: Zygote arrest I (Zarl) is an evolutionarily conserved gene expressed in vertebrate ovaries. Biol Reprod 2003, 69:86I-867.

13. Elis S, Batellier F, Couty I, Balzergue S, Martin-Magniette ML, Monget $P$, Blesbois $E$, Govoroun MS: Search for the genes involved in oocyte maturation and early embryo development in the hen. BMC Genomics 2008, 9:। I0.

14. Colledge WH, Carlton MB, Udy GB, Evans MJ: Disruption of c-mos causes parthenogenetic development of unfertilized mouse eggs. Nature 1994, 370:65-68

15. Hashimoto $N$, Watanabe $N$, Furuta $Y$, Tamemoto $H$, Sagata $N$ Yokoyama M, Okazaki K, Nagayoshi M, Takeda N, Ikawa Y: Parthenogenetic activation of oocytes in c-mos-deficient mice. Nature 1994, 370:68-7|.

16. Kim MH, Yuan X, Okumura S, Ishikawa F: Successful inactivation of endogenous Oct-3/4 and c-mos genes in mouse preimplantation embryos and oocytes using short interfering RNAs. Biochem Biophys Res Commun 2002, 296: I372-1377.

17. Sagata N, Watanabe N, Woude GF Vande, lkawa Y: The c-mos proto-oncogene product is a cytostatic factor responsible for meiotic arrest in vertebrate eggs. Nature 1989, 342:512-518.

18. Kajiura-Kobayashi H, Yoshida N, Sagata N, Yamashita M, Nagahama Y: The Mos/MAPK pathway is involved in metaphase II arrest as a cytostatic factor but is neither necessary nor sufficient for initiating oocyte maturation in goldfish. Dev Genes Evol 2000, $210: 416-425$

19. Newman B, Dai Y: Transcription of c-mos protooncogene in the pig involves both tissue-specific promoters and alternative polyadenylation sites. Mol Reprod Dev 1996, 44:275-288.

20. Propst F, Woude GF Vande: Expression of c-mos proto-oncogene transcripts in mouse tissues. Nature 1985,3 |5:5 |6-5 I8.
21. Fasano S, Chieffi P, Minucci S, Le Guellec K, Jegou B, Pierantoni R: Detection of c-mos related products in the dogfish (Scyliorhinus canicula) testis. Mol Cell Endocrinol 1995, I09:| 27-I 32.

22. Matsuda S, Rouault J, Magaud J, Berthet $C$ : In search of a function for the TIS2I/PC3/BTGI/TOB family. FEBS Lett 200I, 497:67-72.

23. Guehenneux F, Duret L, Callanan MB, Bouhas R, Hayette S, Berthet C, Samarut C, Rimokh R, Birot AM, Wang Q, Magaud JP, Rouault JP: Cloning of the mouse BTG3 gene and definition of a new gene family (the BTG family) involved in the negative control of the cell cycle. Leukemia 1997, I I:370-375

24. Yoshida Y, Matsuda S, Ikematsu N, Kawamura-Tsuzuku J, Inazawa J, Umemori $\mathrm{H}$, Yamamoto T: ANA, a novel member of Tob/BTGI family, is expressed in the ventricular zone of the developing central nervous system. Oncogene 1998, 16:2687-2693.

25. Feng Z, Tang ZL, Li K, Liu B, Yu M, Zhao SH: Molecular characterization of the BTG2 and BTG3 genes in fetal muscle development of pigs. Gene 2007, 403:170-I77.

26. Pennetier S, Uzbekova S, Guyader-Joly C, Humblot P, Mermillod P, Dalbies-Tran R: Genes preferentially expressed in bovine oocytes revealed by subtractive and suppressive hybridization. Biol Reprod 2005, 73:713-720.

27. Carabatsos MJ, Elvin J, Matzuk MM, Albertini DF: Characterization of oocyte and follicle development in growth differentiation factor-9-deficient mice. Dev Biol 1998, 204:373-384.

28. Dong J, Albertini DF, Nishimori K, Kumar TR, Lu N, Matzuk MM: Growth differentiation factor-9 is required during early ovarian folliculogenesis. Nature 1996, 383:531-535.

29. Ross-Macdonald P, Roeder GS: Mutation of a meiosis-specific MutS homolog decreases crossing over but not mismatch correction. Cell 1994, 79:1069-1080.

30. Santucci-Darmanin S, Vidal F, Scimeca JC, Turc-Carel C, Paquis-Flucklinger V: Family of SRY/Sox proteins is involved in the regulation of the mouse Msh4 (MutS Homolog 4) gene expression. Mol Reprod Dev 200I, 60: I72-180.

31. Kneitz B, Cohen PE, Avdievich E, Zhu L, Kane MF, Hou H Jr, Kolodner RD, Kucherlapati R, Pollard JW, Edelmann W: MutS homolog 4 localization to meiotic chromosomes is required for chromosome pairing during meiosis in male and female mice. Genes Dev 2000, I 4:1085-1097.

32. Dade S, Callebaut I, Mermillod P, Monget P: Identification of a new expanding family of genes characterized by atypical LRR domains. Localization of a cluster preferentially expressed in oocyte. FEBS Lett 2003, 555:533-538.

33. Boguski MS, Lowe TM, Tolstoshev CM: dbEST - database for "expressed sequence tags". Nat Genet 1993, 4:332-333.

34. Govoroun M, Le Gac F, Guiguen Y: Generation of a large scale repertoire of Expressed Sequence Tags (ESTs) from normalised rainbow trout cDNA libraries. BMC Genomics 2006, 7:196.

35. Gouret P, Vitiello V, Balandraud N, Gilles A, Pontarotti P, Danchin EG: FIGENIX: intelligent automation of genomic annotation: expertise integration in a new software platform. BMC Bioinformatics 2005, 6:198.

36. Flicek P, Aken BL, Beal K, Ballester B, Caccamo M, Chen Y, Clarke L, Coates G, Cunningham F, Cutts T, Down T, Dyer SC, Eyre T, Fitzgerald S, Fernandez-Banet I, Graf S, Haider S, Hammond M, Holland R, Howe KL, Howe K, Johnson N, Jenkinson A, Kahari A, Keefe D, Kokocinski F, Kulesha E, Lawson D, Longden I, Megy K, et al.: Ensembl 2008. Nucleic Acids Res 2008, 36:D707-D7|4.

37. Saitou N, Nei M: The neighbor-joining method: a new method for reconstructing phylogenetic trees. Mol Biol Evol 1987, 4:406-425.

38. Felsenstein J: Evolutionary trees from DNA sequences: a maximum likelihood approach. I Mol Evol I98I, I 7:368-376.

39. Nei M: Phylogenetic analysis in molecular evolutionary genetics. Annu Rev Genet 1996, 30:371-403.

40. Billard R: Reproduction in rainbow trout: sex differentiation, dynamics of gametogenesis, biology and preservation of gametes. Aqua 1992, 100:263-298.

41. Bobe J, Nguyen T, Jalabert B: Targeted Gene Expression Profiling in the Rainbow Trout (Oncorhynchus mykiss) Ovary During Maturational Competence Acquisition and Oocyte Maturation. Biol Reprod 2004, 71:73-82. 